\title{
In-Stent Stenosis Following Covered Stent-Graft Placement
}

\author{
Justin Flood, Miguel Bussière, Patrick Teefy, Irene Gulka, Stephen Lownie, David Pelz
}

Can. J. Neurol. Sci. 2009; 36: 248-251

Internal carotid artery (ICA) covered stent-grafts are increasingly utilized for the endovascular management of traumatic carotid pseudoaneurysms $\mathrm{s}^{1-9}$, carotid-cavernous fistulas $^{10-12}$, large petrous/cavernous carotid aneurysms ${ }^{12}$ and carotid blow-out syndrome ${ }^{7}$. Early covered stent grafts were selffabricated using polytetrafluoroethylene or autologous vein mounted onto bare metal stents. Pre-mounted balloon expandable or self-expanding stent-grafts are now commercially available. Covered stents provide an alternate treatment option for high surgical risk or inaccessible lesions or when observation and anticoagulation are less than desirable. Potential advantages of covered stent grafts include minimal invasiveness, shorter hospital stays, lower cost and less post-procedural pain. Caution in the application of this relatively new technology and careful follow-up are required, however, as is illustrated by two patients with internal carotid artery stenosis following covered stent-graft placement.

\section{Case 1}

A 24-year-old previously healthy right-handed woman was the belted driver in a vehicle roll-over. She sustained multiple injuries including fractures of the odontoid process of $\mathrm{C} 2$ and the left transverse process of C7. A computed tomogram (CT) head performed at the time of admission was unremarkable. The patient was sedated, intubated and treated with hypothermia according to the institutional protocol. As the sedation dissipated 24-hours later, the patient was found to be aphasic with mild right-sided face and arm weakness. A repeat CT head demonstrated a subacute left fronto-temporal infarct and CT angiography revealed left internal carotid artery (ICA) occlusion, presumed to be secondary to arterial dissection. Antiplatelet therapy was initiated at this time.

The patient made a good functional recovery with significant improvement in speech and complete recovery of motor function. A one-month follow-up CT angiogram demonstrated recanalization of the left ICA but development of a pseudoaneurysm at the level of the first cervical vertebrae. Serial noninvasive angiography over three months demonstrated progressive enlargement of the pseudoaneurysm and consequently the patient was referred for endovascular management to prevent its continued expansion and decrease the future risk of a recurrent ischemic event.

Given the angio-architecture of the pseudoaneurysm, covered stent graft placement or vessel occlusion were considered as the safest and effective treatment options. An approach preserving

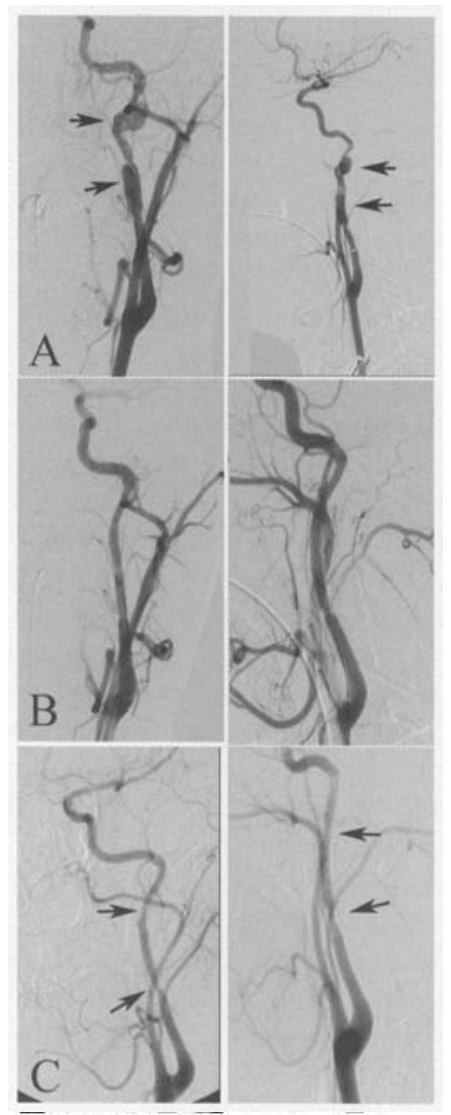

Figure 1: Digital subtraction angiography of traumatic carotid pseudoaneurysms. Left ICA digital subtraction angiography (Anteriorposterior and lateral views) at presentation (IA) demonstrating two pseudoaneurysms (arrows) associated with 50\% ICA stenosis. After covered stent placement $(I B)$ the pseudoaneurysms are obliterated and lumen size is normalized. At one year follow-up $(I C)$, two areas of $50 \%$ in-stent restenosis are observed (arrows).

From the Division of Neuroradiology (JF, MB, IG, SL. DP), Department of Medical Imaging: Department of Clinical Neurological Sciences (MB. IG, SL.DP), Division of Cardiology (PT), Department of Medicine, London Health Sciences Centre, University of Western Ontario, London, Ontario, Canada.

Received May 22, 2008. Final Revisions Submittia) Novimber 4, 2008. Correspondence to: David Pelz, Depts of Medical Imaging and Clinical Neurological Sciences, Neuroradiology, University of Western Ontario, 339 Windermere Road. London, Ontario, N6A 5A5, Canada. 
the patency of the ICA was favoured. Prior to stenting, however, a balloon test occlusion was performed to determine whether ICA occlusion was an option in the event of an inadvertent procedural complication or if covered stent placement was unsuccessful. The patient successfully tolerated 30 minutes of left ICA occlusion without development of new focal deficits but unfortunately developed a second more proximal iatrogenic pseudoaneurysm (Figure 1A).

The patient was maintained on continuous combined acetylsalicylic acid and clopidogrel anti-platelet therapy prior to and after stent placement and systemic anticoagulation was utilized throughout the stenting procedure. Intravascular ultrasound demonstrated the wide base of the pseudoaneurysms (Figure 2A). Two balloon-expandable $4 \mathrm{~mm} \times 26 \mathrm{~mm}$ Jostent covered stents (Abbott Vascular, Abbott Park, IL) were sequentially centered over each pseudoaneurysm and deployed. Precise appositioning of the ends of the stents was confirmed by intravascular ultrasound (Figure 2B). Digital subtraction angiography confirmed complete obliteration of the pseudoaneurysms (Figure 1B).

Unfortunately, cerebral angiography at one year follow-up demonstrated two new focal areas of moderate stenosis within the stents (Figure 1C) due to intimal hyperplasia. Careful monitoring of this young patient continues.

\section{Case 2}

A 59-year-old right-handed female presented with a two year

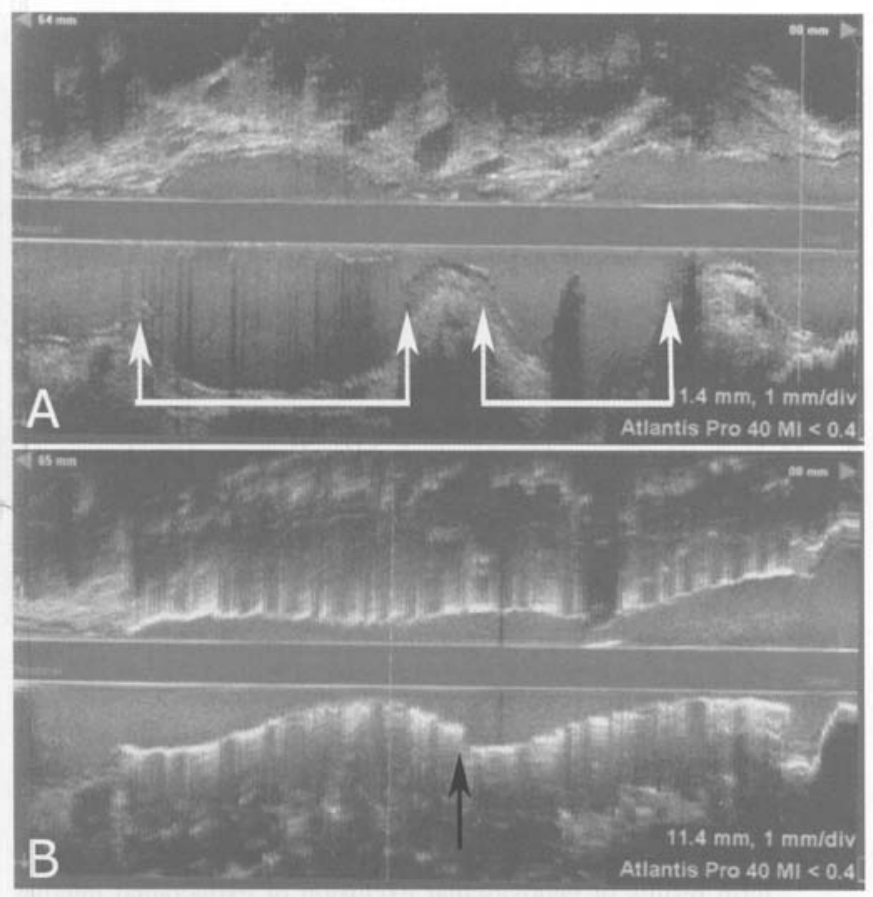

Figure 2: Intravascular ultrasound demonstrating the wide base of the pseudoaneurysms ( $2 \mathrm{~A}$, white arrows). Subsequent to covered stent placement, stent apposition (black arrow) and complete aneurysm occlusion are confirmed $(2 B)$. history of visual blurring eventually developing into frank vertical diplopia and ptosis due to right third cranial nerve paresis. Imaging revealed a giant three centimeter right cavernous carotid artery aneurysm (Figure 3A). Treatment options considered included vessel occlusion or covered stentgraft placement. Preservation of the patency of the ICA was preferred over arterial occlusion. Once again, a balloon test occlusion was performed to determine whether ICA occlusion was an option in the event of an inadvertent procedural complication or if covered stent placement was unsuccessful. The patient did not tolerate temporary occlusion of the right ICA, developing a left pronator drift and hand clumsiness. A concomitant $99 \mathrm{mTc}$-hexamethyl propyleneamine oxime single photon emission computed tomography study confirmed decreased perfusion to the right hemisphere. Consequently, a left extracranial-to-intracranial artery bypass (superficial temporal to middle cerebral) was performed. The patient tolerated 30 minutes of vessel occlusion without developing focal deficits after the bypass.

A $4 \mathrm{~mm} \times 26 \mathrm{~mm}$ balloon-expandable Jostent was uneventfully positioned across the base of the giant cavernous aneurysm, resulting in its complete exclusion (Figure 3B). Systemic heparinization was maintained throughout the procedure and the patient was discharged on daily clopidogrel and acetylsalicylic acid. Due to bruising and epistaxis, the acetylsalicylic acid was later reduced to alternate day dosing. Over the following six months, the patient's third nerve paresis improved significantly and follow-up non-invasive imaging demonstrated complete aneurysm regression but mild stenosis within the stented artery. At one year follow-up, however, cerebral angiography revealed occlusion of the right ICA just distal to the carotid bulb (Figure 3C), likely secondary to intimal hyperplasia, though subacute thrombosis cannot be entirely ruled out. On careful questioning, the patient reported subjectively decreased strength in the left arm.

Several studies have reported good technical success for the treatment of internal carotid artery injuries with covered stent grafts $^{1-4,7-12}$. The few complications reported include subacute thrombosis or intimal hyperplasia leading to stenosis or complete vessel occlusion ${ }^{1-4,6.7}$. Subacute thrombosis is thought to be more common with covered stents ${ }^{13}$. Cothren et al ${ }^{14}$ reported a $45 \%$ occlusion rate three to six months following stent placement, despite concurrent anticoagulation. Conversely, only $5 \%$ of patients treated with anticoagulation alone proceeded to complete occlusion. Traumatic injury to the carotid artery may produce a hypercoagulable state. When compounded by decreased flow through the stent graft, this may contribute to a high rate of occlusion ${ }^{14}$. Other factors contributing to carotid stent occlusion include small vessel size, dissection and underdilation of the stent ${ }^{1}$.

Redekop et $\mathrm{al}^{1}$ and Duane et $\mathrm{al}^{3}$ have described asymptomatic complete ICA occlusion following stent grafting, the former for treatment of a traumatic petrous-cavernous ICA pseudoaneurysm and the latter for a traumatic skull base ICA pseudoaneurysm. After stent deployment, there was persistent narrowing at the end of the stent due to an intimal flap, which may have been the cause of the occlusion. Two reports of asymptomatic complete ICA occlusion have been described following carotid cavernous fistula repair ${ }^{10,11}$. Other patients developed mild intimal 


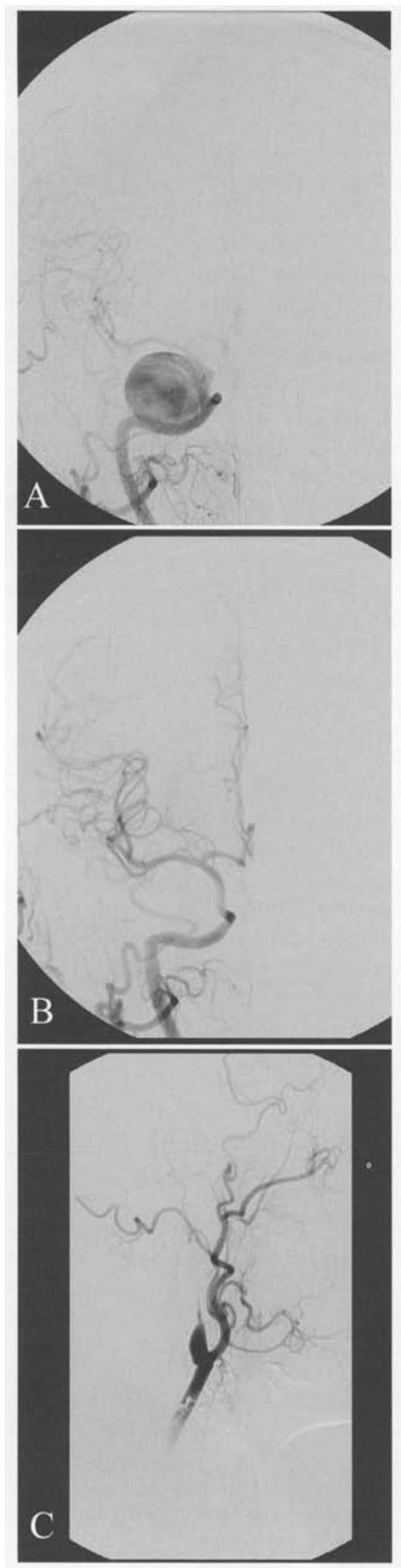

Figure 3: Digital subtraction angiography of giant cavernous carotid aneurysm. Right ICA digital subtraction angiography at presentation (3A; Anterior-Posterior and lateral views) demonstrating the giant cavernous carotid aneurysm. Subsequent to covered stent placement $(3 B)$ complete aneurysm exclusion is observed. Asymptomatic cervical ICA occlusion was seen at one year follow-up $(3 C)$. hyperplasia within the stent ${ }^{10,11}$. McNeil et $\mathrm{al}^{2}$ and Parodi et $\mathrm{al}^{4}$ described $50 \%$ and $90 \%$ restenosis of the ICA in two patients following management of traumatic pseudoaneurysms with stent grafts. The latter progressed to complete occlusion 39 months after initial stent graft placement.

The true incidence of restenosis after ICA stent graft placement is unknown. The in-stent stenosis rate for bare metal stents in larger studies has been estimated at $4-5 \%{ }^{15}$. Maras et al ${ }^{13}$ reviewed 20 patients of traumatic pseudoaneurysms treated with covered stent grafts and found a $15 \%$ occlusion rate. The patients had variable follow-up ranging from 6 to 23 months. Another patient had a 50\% stenosis at ten months. Saatci et al ${ }^{5}$ reported no cases of restenosis following management of 24 petrous/cavernous ICA aneurysms with stent grafting. Follow-up ranged from six months to two years. The synthetic layer of stent grafts is thought to act as a mechanical barrier allowing only minimal intimal hyperplasia. End-stent stenosis is more common with covered stents compared with conventional stents ${ }^{16}$ and it has been suggested that it primarily occurs adjacent to a bend or kink $^{17}$.

Treatment of carotid artery injury or abnormalities with covered stent-grafts is a relatively new procedure. Large trials and long-term studies supporting the use of covered stent-grafts are lacking, but are required to determine the true incidence of complications of stent-graft use and identify patients at risk for these complications. The two cases described above, and a review of the case reports and series reported in the literature, demonstrate that in-stent stenosis and subacute thrombosis can complicate covered stent placement. Caution in the application of this relatively new technology and careful clinical and angiographic follow-up are mandatory.

\section{ACKNOWLEDGEMENTS}

Author MB receives fellowship funding from the Heart and Stroke Foundation of Canada, AstraZeneca Canada and a Resident Research Career Development Award from the Schulich School of Medicine \& Dentistry, University of Western Ontario.

\section{REFERENCES}

1. Redekop G, Marotta T, Weill A. Treatment of traumatic aneurysms and arteriovenous fistulas of the skull base by using endovascular stents. J Neurosurg. 2001;95:412-19.

2. McNeil JD, Chiou AC, Gunlock MG, Grayson DE, Soares G, Hagino RT. Successful endovascular therapy of a penetrating zone III internal carotid injury. I Vasc Surg. 2002;36:187-90.

3. Duane TM, Parker F, Stokes GK, Parent FN, Britt LD. Endovascular carotid stenting after trauma. J Trauma. 2002;52: 149-53.

4. Parodi JC, Schönholz C, Ferreira LM, Bergan J. Endovascular stent-graft treatment of traumatic arterial lesions. Ann Vasc Surg. 1999;13:121-9.

5. Saatci I, Cekirge HS, Ozturk MH, Arat A, Ergungor F, Sekerci Z, et al. Treatment of internal carotid artery aneurysms with a covered stent: experience in 24 patients with mid-term follow-up results. AJNR Am J Neuroradiol. 2004;25:1742-9.

6. Bergeron P, Khanoyan P, Meunier JP, Graziani JN, Gay J. Longterm results of endovascular exclusion of extracranial internal carotid artery aneurysms and dissecting aneurysm. J Interv Cardiol. 2004; 17:245-52.

7. Hoppe H, Barnwell SL, Nesbit GM, Petersen BD. Stent-grafts in the treatment of emergent or urgent carotid artery disease: review of 25 cases. J Vasc Interv Radiol. 2008;19:31-41. 
8. Layton KF, Kim YW, Hise JH. Use of covered stent grafts in the extracranial carotid artery: report of three patients with followup between 8 and 42 months. AJNR Am J Neuroradiol. 2004;25: $1760-3$.

9. Simionato F, Righi C, Melissano G, Rolli A, Chiesa R, Scottiet G. Stent-graft treatment of a common carotid artery pseudoaneurysm. J Endovasc Ther. 2000;7:136-40.

10. Gomez F, Escobar W, Gomez AM, Gomez JF, Anaya CA. Treatment of carotid cavernous fistulas using covered stents: midterm results in seven patients. AJNR Am J Neuroradiol. 2007;28: $1762-8$.

11. Archondakis E, Pero G, Valvassori L, Boccardi E, Scialfa G. Angiographic follow-up of traumatic carotid cavernous fistulas treated with endovascular stent graft placement. AJNR Am J Neuroradiol. 2007;28:342-7.

12. Alexander MJ, Smith TP, Tucci DL. Treatment of an iatrogenic petrous carotid artery pseudoaneurysm with a Symbiot covered stent: technical case report. Neurosurgery. 2002;50:658-62.
13. Maras D, Lioupis C, Magoufis G, Tsamopoulos N, Moulakakis K, Andrikopoulos V. Covered stent-graft treatment of traumatic internal carotid artery pseudoaneurysms: a review. Cardiovasc Intervent Radiol. 2006;29:958-68.

14. Cothren CC, Moore EE, Ray CE Jr, Ciesla DJ, Johnson JL, Moore JB, et al. Carotid artery stents for blunt cerebrovascular injury; risks exceed benefits. Arch Surg. 2005;140:480-6.

15. Setacci C, Pula G, Baldi I, de Donato G, Setacci F, Cappelliet A, et al. Determinants of in-stent restenosis after carotid angioplasty: a case-control study. J Endovasc Ther. 2003;10:1031-8.

16. Gercken U, Lansky AJ, Buellesfeld L, Desai K, Badereldin M, Mueller R, et al. Results of the Jostent coronary stent graft implantation in various clinical settings: procedural and followup results. Catheter Cardiovasc Interv. 2002;56:353-60.

17. Willfort-Ehringer A, Ahmadi R, Gschwandtner ME, Haumer M, Lang W, Minar E. Single center experience with carotid stent restenosis. J Endovasc Ther. 2002;9:299-307. 